\title{
ECOLOGIA E PROJEÇÃO DIAMÉTRICA DE TRÊS GRUPOS ARBÓREOS EM REMANESCENTE DE FLORESTA OMBRÓFILA MISTA EM SÃO FRANCISCO DE PAULA, RS
}

\author{
Angelo Augusto Ebling ${ }^{1}$, Sylvio Péllico Netto ${ }^{2}$, Luciano Farinha Watzlawick ${ }^{3}$, \\ Rodrigo Otávio Veiga de Miranda ${ }^{4}$, Simone Filipini Abrão ${ }^{5}$ \\ ${ }^{1}$ Eng. Florestal, M.Sc., Doutorando em Eng. Florestal, UFPR, Curitiba, PR, Brasil - aebling @ hotmail.com \\ ${ }^{2}$ Eng. Florestal, Dr., Depto. de Ciências Florestais, UFPR, Curitiba, Brasil - sylviopelliconetto@ gmail.com \\ ${ }^{3}$ Eng. Florestal, Dr., Depto. de Agronomia, UNICENTRO, Guarapuava, PR, Brasil - luciano.watzlawick @pq.cnpq.br \\ ${ }^{4}$ Eng. Florestal, M.Sc., Doutorando em Eng. Florestal, UFPR, Curitiba, PR, Brasil - rov_miranda@yahoo.com.br \\ ${ }^{5}$ Eng. Florestal, M.Sc., Téc. Administrativa em Educação, UFPR, Curitiba, PR, Brasil - simone.abrao@ufpr.br
}

Recebido para publicação: 20/08/2012 - Aceito para publicação: 11/03/2013

\begin{abstract}
Resumo
A Floresta Ombrófila Mista desempenha importante função social e ecológica na região Sul do Brasil. Embora tenha sofrido um profundo processo exploratório, resultando em sua fragmentação, apresenta elevado potencial para o manejo que, devidamente aplicado, favorece a conservação e recuperação de seus remanescentes. Com o objetivo de avaliar o incremento diamétrico e a dinâmica sucessional dessa fitofisionomia, foram empregados dados oriundos do estrato arbóreo (DAP $\geq 9,5 \mathrm{~cm}$ ) de 10 parcelas permanentes de 1 ha cada, remedidas anualmente entre o período de 2000 a 2009, na Floresta Nacional de São Francisco de Paula, RS. As observações e projeções indicaram gradual redução da densidade da floresta, com destaque para a espécie Araucaria angustifolia (Bertol.) Kuntz., entretanto, observou-se tendência de aumento na densidade da família Lauraceae. O período de meia vida estimado para a floresta foi de 97 anos e, para Araucaria angustifolia, 332 anos. As estimativas ainda sugerem que, em 71 anos, as espécies de Lauraceae devem duplicar sua densidade. O crescimento da floresta foi inferior ao da família Lauraceae ( $\overline{\mathrm{IPD}}=0,175 \mathrm{~cm} /$ ano e $\overline{\mathrm{IPD}}=0,179 \mathrm{~cm} / \mathrm{ano}$, respectivamente) e a Araucaria angustifolia manteve o menor crescimento $(\overline{\mathrm{IPD}}=0,159 \mathrm{~cm} / \mathrm{ano})$. As análises indicaram um avanço sucessional, com a gradual substituição da Araucaria angustifolia por espécies com maior adaptação às condições de equilíbrio.
\end{abstract}

Palavras-chave: Família Lauraceae; Floresta com Araucária; sucessão florestal.

\begin{abstract}
Ecology and diametric projection of three arboreal groups in a Mixed Ombrophilous Forest fragment in São Francisco de RS, Brazil. The Mixed Ombrophylous Forest performs an important social and ecological function in southern Brazil. Although it has suffered a profound exploratory process, resulting in their fragmentation, it has a high potential for management that, properly applied, promotes conservation and recovery of their remains. In order to assess the increment in diameter and dynamics of phytophisiognomy, this research used data from the tree strata $(\mathrm{DBH} \geq 9.5 \mathrm{~cm})$ of 10 permanent plots of 1 ha each remeasured annually between the period 2000 to 2009 in São Francisco de Paula National Forest, RS, Brazil. The observations and projections indicate a gradual reduction in the forest density, showing up Araucaria angustifolia (Bertol.) Kuntze species, however, for the Lauraceae species, there was a tendency of increase. The period of half-life estimated for the forest was 97 years and for Araucaria angustifolia, 332 years. The estimates also suggested that in 71 years, the Lauraceae should double its density. The forest growth was lower than that observed in the Lauraceae (IPD $=0.175 \mathrm{~cm} /$ year and $\overline{\mathrm{IPD}}=0.179 \mathrm{~cm} /$ year, respectively) and Araucaria angustifolia maintained the lowest growth ( $\overline{\mathrm{IPD}}=0.159 \mathrm{~cm} / \mathrm{year}$ ). The analysis indicated a positive advance, with the gradual replacement of Araucaria angustifolia by other species with greater adaptation to the successional conditions. Keywords: Araucaria Forest; Lauraceae family; forest succession.
\end{abstract}

\section{INTRODUÇÃO}

O bioma Mata Atlântica se estende da região Sul à Norte do Brasil e, embora tenha sofrido com diferentes ciclos exploratórios, é considerado um "hotspot", com grande importância para a conservação, 
manutenção e sustentação dos recursos naturais e comunidades típicas. O bioma conta com grande número de endemismos e marcantes fitofisionomias, das quais se pode destacar a Floresta Ombrófila Mista, cuja ocorrência natural é o Planalto Meridional brasileiro.

A expansão da Floresta Ombrófila Mista sobre o Planalto teve início em torno de 3.210 anos antes do presente (A.P.), migrando de matas de galeria ao longo de rios, sendo que, na primeira parte do Holoceno superior (4.320 até 1.100 anos A.P.), a Araucaria angustifolia se expandiu na região Nordeste do estado do Rio Grande do Sul, avançando sobre os campos (BEHLING et al., 2009; BEHLING; LICHTE, 1997). Atualmente, as modificações do clima, associadas com exploração indiscriminada, expulsam o que resta da Floresta Mista para as grandes altitudes ou altas latitudes, cedendo espaço às Florestas Estacionais (GALVÃO; AUGUSTIN, 2011). Nesse sentido, Klein (1978) sugere um modelo de sucessão com o avanço da Floresta Estacional em detrimento natural da Floresta Ombrófila Mista.

O manejo racional de florestas está diretamente relacionado ao suprimento matéria-prima, sem comprometer o equilíbrio do ecossistema e disponibilidade futura de recursos, porém sua aplicabilidade fica sujeita às informações da dinâmica florestal, que ainda carece de estudos com maior aprofundamento. Poucas são as informações disponíveis sobre o crescimento arbóreo, seja de áreas intactas, seja de áreas exploradas, ou ainda, de áreas sujeitas a regime de manejo (SCOLFORO et al., 1998), que pode resultar na falta de compatibilidade entre os objetivos esperados e os resultados encontrados pelo manejador (AUSTREGÉSILO et al., 2004).

Diante do exposto, neste trabalho foram analisados aspectos ecológicos e sucessionais da Floresta Ombrófila Mista, considerando suas características dinâmicas. Para isso, foram avaliados o crescimento e a estrutura e realizadas projeções da floresta, empregando-se dados oriundos de inventário florestal contínuo da Flona de São Francisco de Paula, RS. As análises foram aplicadas considerando-se três categorias: a primeira para toda a comunidade arbórea da floresta; a segunda, de forma seletiva, para a família Lauraceae; e a terceira, para Araucaria angustifolia que, além de elevado potencial silvicultural, funciona como um indicativo dos processos sucessionais que atuam na floresta.

\section{MATERIAL E MÉTODOS}

O estudo foi realizado na Flona de São Francisco de Paula, localizada entre as coordenadas $29^{\circ} 24^{\prime}$ e $29^{\circ} 27^{\prime}$ de latitude sul e $50^{\circ} 22^{\prime}$ e $50^{\circ} 25^{\prime}$ de longitude oeste, na mesorregião nordeste do estado do Rio Grande do Sul.

O relevo local é considerado ondulado a fortemente ondulado, com altitude média de $900 \mathrm{~m}$ acima do nível do mar. Os solos que caracterizam a região são classificados como Cambissolo Húmico Alumínico, Chernossolo Argilúvico Férrico e Neossolo Litólico Eutrófico (EMPRESA BRASILEIRA DE PESQUISA AGROPECUÁRIA (EMBRAPA), 2006), derivados de rochas efusivas básicas e ácidas da Formação Serra Geral (KAUL, 1990).

O clima da região é do tipo $\mathrm{Cfb}$, mesotérmico e superúmido, com verões brandos e invernos frios, com frequente formação de geadas e queda de neve nos meses mais frios. A precipitação local consiste em uma das mais elevadas do Rio Grande do Sul, com $2.162 \mathrm{~mm}$, distribuída de forma regular por todo período anual (MALUF, 2000).

Os dados utilizados neste estudo são provenientes de inventário florestal contínuo, empregandose uma amostragem com repetição total, constituída por 10 parcelas com área de 1 ha $(100$ x $100 \mathrm{~m})$ cada, distribuídas dentro da vegetação natural da unidade de conservação. Todos os indivíduos arbóreos com diâmetro à altura do peito igual ou superior a $9,5 \mathrm{~cm}(\mathrm{DAP} \geq 9,5 \mathrm{~cm})$ foram identificados no nível de espécie e tiveram suas características dendrométricas mensuradas anualmente, período em que foram avaliados, também, os recrutamentos e a mortalidade.

Com base nos dados inventariados entre os anos de 2000 e 2009, foram realizadas análises referentes às alterações da estrutura horizontal. A metodologia empregada para as projeções dos diâmetros foi a razão de movimentação, definida por Scolforo et al. (1998) como a proporção do número de árvores que avançam entre as classes diamétricas em função do incremento diamétrico. A razão de movimentação foi calculada com base nos processos dinâmicos da floresta, inventariados entre os anos de 2006 e 2009. O modelo de projeção empregado no estudo (modelo matemático, amplitude temporal, intervalo de classes diamétricas) foi escolhido por se tratar da metodologia mais acurada para cálculos de projeção na floresta em questão, conforme Ebling et al. (2012). Foram aplicadas três projeções consecutivas, visando estimar a estrutura diamétrica para o ano de 2021, sugerir a proporção de migração de indivíduos para classes diamétricas superiores e, com isso, definir a estrutura futura da floresta. 
Com o objetivo de avaliar o comportamento estrutural observado e projetado da comunidade florestal, foram realizadas análises em três populações amostrais, ou categorias: a primeira consistiu na avaliação de todos os indivíduos arbóreos da floresta; a segunda dos indivíduos da família Lauraceae; e, por fim, a terceira categoria, constituída pelos indivíduos da espécie Araucaria angustifolia.

A escolha da família Lauraceae para os cálculos de projeção se deu à sua representatividade ecológica e potencial para o manejo, avaliada por meio dos parâmetros fitossociológicos das espécies que a compõem e pelas informações disponíveis na literatura. As espécies que compõem o estrato arbóreo dessa família na Flona de São Francisco de Paula são: Cinnamomum amoenum (Nees) Kosterm., Cinnamomum glaziovii (Mez) Kosterm., Cryptocarya aschersoniana Mez, Cryptocarya moschata Nees \& C. Mart., Nectandra megapotamica (Spreng.) Mez, Ocotea indecora Schott ex Meissner, Ocotea porosa (Nees \& Mart.) Barroso, Ocotea puberula (Rich.) Nees e Ocotea pulchella Mart. Com critérios seletivos semelhantes, se justifica a escolha da espécie Araucaria angustifolia nas análises.

Com base nos dados observados e projetados, realizou-se uma análise gráfica da distribuição diamétrica observada e projetada. Complementar a isso, foi realizada a análise gráfica do incremento periódico em diâmetro (IPD) e o desvio padrão para cada categoria avaliada, com base no mesmo período empregado para as projeções.

Ainda, o período de duplicação e de meia vida foram aplicados às três categorias de populações selecionadas, sendo a meia vida àquelas com tendência de redução da densidade e o período de duplicação àquelas populações com tendência ao seu aumento.

$\mathrm{O}$ período de meia vida da floresta $\left(\mathrm{t}_{0,5}\right)$, considerado como o tempo (em anos) para a floresta reduzir pela metade sua densidade, descrito por Korning e Balslev (1994) como um modelo algébrico, é baseado na mortalidade anual $(r)$ em um dado período $(\mathrm{t})$, capaz de estimá-la como segue:

$$
r={\frac{C_{1}}{C_{0}}}^{\frac{1}{t}}-1
$$

Em que: $r=$ corresponde à taxa anual de mortalidade;

$t=$ período de tempo analisado;

$C_{0}$ e $C_{l}=$ densidade da primeira e última análise.

O período de meia vida foi obtido partir da expressão:

Em que: $t_{0,5}=$ período de meia vida;

$$
t_{0,5}=\frac{\operatorname{Ln} \frac{1}{2}}{\operatorname{Ln}(1-r)}
$$

$L n=$ logaritmo de base neperiana;

$r=$ taxa anual de mortalidade.

O período de duplicação, definido por Korning e Balslev (1994) como o tempo necessário para que a densidade dobre seu número inicial devido aos acréscimos ocasionados pelos recrutamentos, é dado pela expressão:

Sendo: $t_{2}=$ período de duplicação;

$$
t_{2}=\frac{\operatorname{Ln} 2}{\operatorname{Ln}(1+r)}
$$

$L n=$ logaritmo de base neperiana;

$r=$ taxa anual de mortalidade.

\section{RESULTADOS E DISCUSSÃO}

A análise da Floresta Nacional em São Francisco de Paula, RS, permitiu inferir que seus processos dinâmicos apontam para um avanço sucessional, manifestado pela redução do número de árvores e crescimento da população arbórea remanescente. O comportamento da estrutura horizontal observada e projetada para a floresta indicou uma redução quanto ao número total de indivíduos, reduzindo de 820,7 ind/ha no ano de 2000 para 707,1 ind/ha no ano de 2021 (redução de 13,8\%) (Tabela 1). 
Características como a redução de densidade e incremento em área transversal foram observadas por Oliveira Filho et al. (2007) e Magnago et al. (2011), configurando um avanço de "sere" da floresta. Gentry e Terborgh (1990) citam que o autodesbaste, associado ao acúmulo de biomassa em pé na floresta, está relacionado às fases avançadas dentro do ciclo silvigenético.

Tabela 1. Frequência de indivíduos observados e projetados para a Floresta Ombrófila Mista, família Lauraceae e Araucaria angustifolia, em São Francisco de Paula, RS.

Table 1. Observed and projected individual frequencies of a Mixed Ombrophylous Forest, Araucaria angustifolia and Lauraceae family, in São Francisco de Paula, RS, Brazil.

\begin{tabular}{lcccccc}
\hline \multirow{2}{*}{ Classes diamétricas (cm) } & \multicolumn{2}{c}{ Floresta Ombrófila Mista } & \multicolumn{2}{c}{ Família Lauraceae } & \multicolumn{2}{c}{ Araucaria angustifolia } \\
\cline { 2 - 7 } & Observado & Projetado & Observado & Projetado & Observado & Projetado \\
\cline { 2 - 7 } & $\mathbf{2 0 0 0}$ & $\mathbf{2 0 2 1}$ & $\mathbf{2 0 0 0}$ & $\mathbf{2 0 2 1}$ & $\mathbf{2 0 0 0}$ & $\mathbf{2 0 2 1}$ \\
\hline $9,5 \vdash-14,5$ & 325,3 & 261,9 & 15,8 & 19,2 & 12 & 10,7 \\
$14,5 \vdash-19,5$ & 164,6 & 133,3 & 11,6 & 13,7 & 12,3 & 10,5 \\
$19,5 \vdash 24,5$ & 96,1 & 79,9 & 10,2 & 9,9 & 9 & 7,6 \\
$24,5 \vdash 29,5$ & 66,0 & 60,2 & 8,4 & 10,2 & 9,3 & 8,9 \\
$29,5 \vdash 34,5$ & 43,6 & 42,1 & 6,1 & 9,0 & 7,9 & 7,2 \\
$34,5 \vdash 39,5$ & 30 & 29,3 & 5,1 & 6,7 & 5,7 & 5,7 \\
$39,5 \vdash 44,5$ & 21,4 & 21,9 & 4,8 & 6,6 & 4,9 & 5,5 \\
$44,5 \vdash-49,5$ & 17,8 & 17,6 & 3,5 & 4,2 & 7,1 & 5,8 \\
$49,5-54,5$ & 15,9 & 15,1 & 1,9 & 3,3 & 8,6 & 7,8 \\
$54,5 \vdash 59,5$ & 12,5 & 12,5 & 1,9 & 2,1 & 6,3 & 6,7 \\
$59,5 \vdash-64,5$ & 9,2 & 10,5 & 1,2 & 1,1 & 6,2 & 6,2 \\
$64,5-69,5$ & 5,7 & 7,0 & 0,5 & 0,8 & 3,6 & 4,8 \\
$69,5 \vdash 74,5$ & 4,4 & 4,4 & 0,4 & 0,6 & 3,5 & 3,1 \\
$74,5 \vdash 79,5$ & 3,5 & 4,4 & 0,3 & 0,5 & 2,5 & 3 \\
$79,5-84,5$ & 1,5 & 2,6 & - & - & 1,2 & 1,8 \\
$84,5 \vdash 89,5$ & 1,4 & 1,8 & - & - & 1,2 & 1,2 \\
$89,5 \vdash 94,5$ & 0,8 & 1,4 & - & - & 0,7 & 1 \\
$94,5 \vdash$ & 1 & 1,2 & - & - & 0,6 & 0,7 \\
\hline Total (ind/ha) & 820,7 & 707,1 & 71,7 & 87,9 & 102,6 & 98,2 \\
\hline
\end{tabular}

As três categorias projetadas apresentaram em comum um leve aumento quanto ao número de indivíduos nas classes diamétricas superiores, propiciado pelo crescimento, que favorece o avanço de classes. No entanto, somente a família Lauraceae indicou aumento quanto ao número de indivíduos na menor classe diamétrica, sendo esse atribuído à superioridade de recrutamentos, que ocorrem exclusivamente nessa classe, em relação ao número de mortalidade.

Contrariando as observações anteriores, a família Lauraceae aumentou sua representatividade no período quanto ao número de indivíduos e, também, em área transversal. Considerando os valores do centro de classe, no ano de 2000 a família ocupava área transversal de $5,7 \mathrm{~m}^{2} / \mathrm{ha}$, sendo a projeção para o ano de $2021 \mathrm{de} 6,9 \mathrm{~m}^{2} / \mathrm{ha}$ (aumento de 21,1\%). Quanto ao número de indivíduos, a projeção indicou um aumento de 22,6\% (71,7 ind/ha no ano de 2000 para 87,9 ind/ha em 2021).

A avaliação do período observado, complementada com o período projetado, permite inferir as características de resiliência da floresta estudada, na qual se observa redução da densidade da floresta e dos indivíduos de Araucaria angustifolia e, concomitante a isso, o avanço da família Lauraceae, com aumento de densidade e diâmetros. De forma sucinta, pode ser estabelecido um modelo sucessional, conforme citado por Rambo (2005), no sentido Campo, Floresta Ombrófila Mista, seguido por Floresta Latifoliada.

Soares (1979) afirma que, em todo continente americano, na associação entre coníferas e folhosas, essas últimas representam as espécies clímax. Dessa forma, justifica-se a substituição natural da espécie Araucaria angustifolia naturalmente pelo avanço de espécies latifoliadas. A limitação dessa espécie é justificada por Behling et al. (2001), devido às condições ambientais atuais, com clima mais úmido, associado a temperaturas médias superiores, entre 5 e $7{ }^{\circ} \mathrm{C}$, relativas ao fim do Pleistoceno (período de instalação da Araucaria angustifolia na região Sul do Brasil). 
Por meio da análise gráfica da estrutura diamétrica da floresta, observa-se o padrão de distribuição exponencial negativo, indicativo de uma floresta balanceada, com capacidade autorregenerativa (Figura 1). O crescimento diamétrico da floresta também evidenciou comportamento assimétrico, em que seus maiores valores ocorreram nas classes superiores. A análise permite inferir uma relação inversa entre densidade de indivíduos e incremento periódico em diâmetro, em que classes diamétricas com maiores densidades apresentam menores valores de incremento. As classes diamétricas intermediárias mantiveram valores semelhantes de incremento, indicando um comportamento semelhante quanto ao crescimento.

O desvio padronizado calculado foi inferior na menor classe diamétrica, devido à alta frequência nela encontrada. Por outro lado, o maior desvio foi verificado para a maior classe diamétrica $(94,5 \vdash \mathrm{cm})$, por englobar indivíduos de grande porte, conferindo características distintas entre os diâmetros.

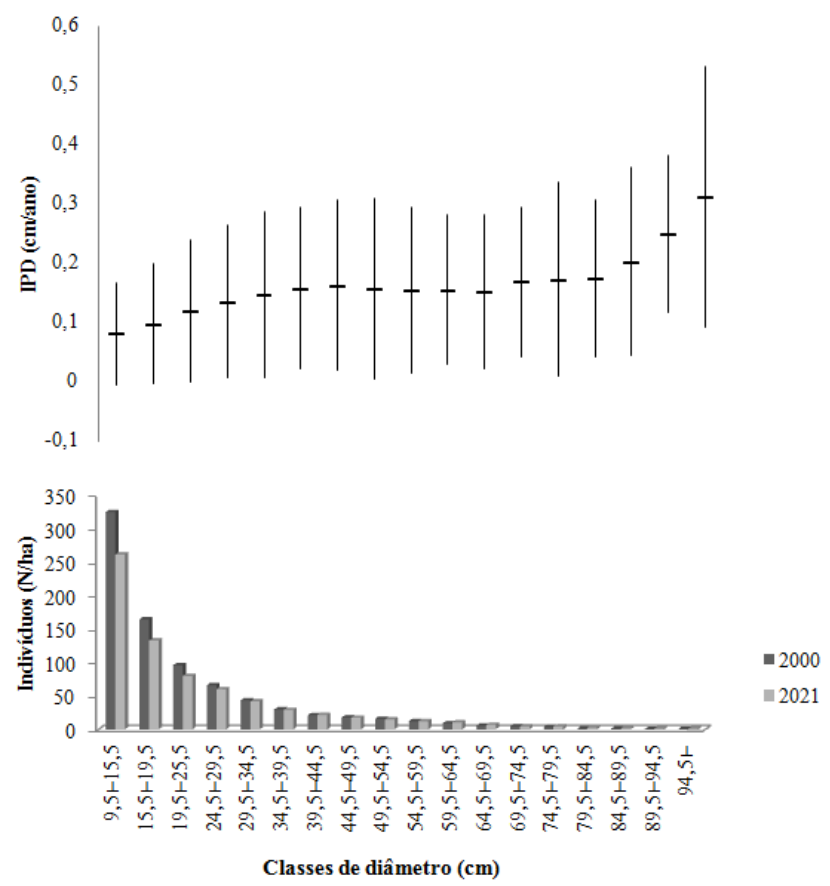

Figura 1. Crescimento em classes diamétricas e distribuição diamétrica para a floresta Ombrófila Mista de São Francisco de Paula, RS.

Figure 1. Diametric growth and diameter distribution for the Mixed Ombrophylous forest of São Francisco de Paula, RS, Brazil.

A floresta apresentou um IPD igual a $0,175 \mathrm{~cm} / \mathrm{ano}$, valor de crescimento inferior se comparado com os trabalhos de Figueiredo Filho et al. (2003), que observou $\overline{\text { IPD }}$ igual a 0,199 cm/ano em uma formação secundária de Floresta Ombrófila Mista no município de Irati, PR, porém, superior ao valor de crescimento descrito no estudo de Barth Filho (2002), que observou $\overline{I P D}$ de 0,127 cm/ano na Floresta Ombrófila Mista de General Carneiro, PR. Moscovich (2006) encontrou valor de IPD igual ao do presente estudo $(0,175 \mathrm{~cm} / \mathrm{ano})$ na Floresta Ombrófila Mista de Nova Prata, RS.

A maior classe diamétrica $(94,5 \vdash \quad \mathrm{cm})$ manteve o maior valor de crescimento (IPD $=0,311 \mathrm{~cm} / \mathrm{ano}$ ), sendo encontrado nessa classe o maior desvio padrão, justificado por ser uma classe aberta e englobar características distintas entre diâmetros. Embora os processos dinâmicos relativos à mortalidade e recrutamento sejam mais intensos na menor classe diamétrica, verificou-se nela o menor crescimento da floresta (IPD $=0,080 \mathrm{~cm} / \mathrm{ano}$ ). 
Considerando-se que as condições dinâmicas e ambientais da floresta sejam constantes (propriedades markovianas), porém observada a inexorável redução de densidade, a floresta alcançará o período de meia vida $\left(t_{0,5}\right)$ em 97,5 anos, período em que o valor de sua densidade reduzirá pela metade.

A família Lauraceae mostrou crescente representatividade na floresta, que pode ser atribuída a seu maior crescimento diamétrico e número de recrutamentos (Figura 2). Pode-se observar que o aumento da representatividade dessa família na floresta indica sua condição de adaptabilidade, com tendência de valorização em sua importância à medida que os processos dinâmicos da floresta avançam. Schaaf et al. (2005), analisando o crescimento de Floresta Ombrófila Mista no Paraná, em estágio secundário avançado, salientam que as Lauráceas constituem as espécies com maior crescimento diamétrico, demonstrando sua adaptação nas florestas nativas, mesmo em formações florestais alteradas em sua formação primária.

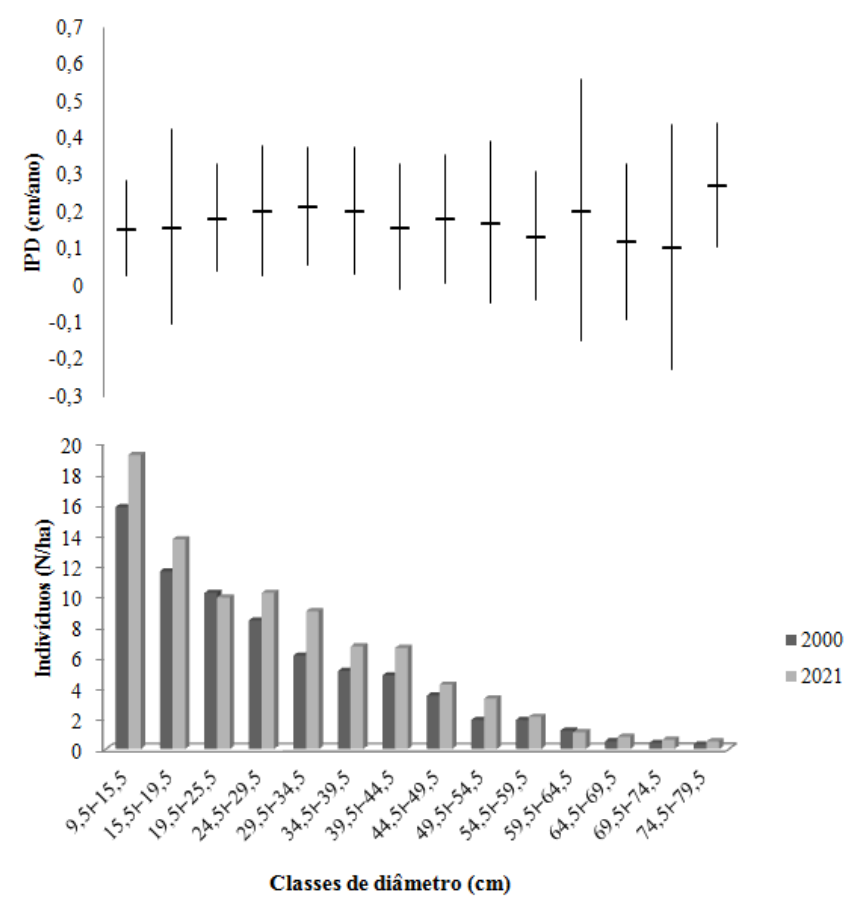

Figura 2. Crescimento em classes diamétricas e distribuição diamétrica para a família Lauraceae na Floresta Ombrófila Mista de São Francisco de Paula, RS.

Figure 2. Diametric growth and diameter distribution for the Lauraceae family in a Mixed Ombrophylous Forest of São Francisco de Paula, RS, Brazil.

Seguindo o observado para a floresta, a distribuição diamétrica da família apresentou um padrão de distribuição exponencial negativo. O crescimento diamétrico da família manteve valor levemente superior ao da floresta $(\overline{\mathrm{IPD}}=0,179 \mathrm{~cm} / \mathrm{ano})$, sendo que as espécies que participaram de forma mais significativa para elevar a média foram Cinnamomum glaziovii ( $\overline{\mathrm{IPD}}=0,226 \mathrm{~cm} / \mathrm{ano}$ ) e Nectandra megapotamica $(\overline{\mathrm{IPD}}=0,215 \mathrm{~cm} / \mathrm{ano}$ ). As mesmas espécies foram as principais responsáveis pelo aumento de densidade na família, representando juntas aproximadamente $60 \%$ dos recrutamentos e menos de $20 \%$ das mortalidades no período avaliado. Seguindo a tendência, as espécies de menor crescimento, Cryptocarya aschersoniana (IPD $=0,137 \mathrm{~cm} / \mathrm{ano}$ ) e Ocotea pulchella $(\overline{\mathrm{IPD}}=0,143 \mathrm{~cm} / \mathrm{ano}$ ) totalizaram $58 \%$ das mortalidades observadas para a família. Não foi observada uma relação entre o avanço de classes diamétricas e o crescimento, podendo isso ser atribuído às características autoecológicas das nove espécies componentes da família, conferindo um caráter diferenciado, com elevado valor de desvio padrão nas classes. 
A heterogeneidade quanto ao crescimento é observado quando avaliadas as classes diamétricas,

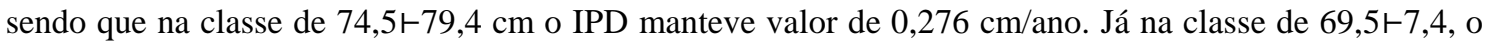
IPD manteve valor de 0,106 cm/ano. As maiores variações entre os incrementos dentro de uma classe foram encontradas na classe de 59,5 $-64,4 \mathrm{~cm}$, resultando em um desvio padrão elevado, justificado pelo pequeno número de árvores ocorrentes nas classes diamétricas superiores, além da ocorrência de assimetria em suas posições no interior dessas classes.

O período avaliado para a família dobrar sua densidade na floresta $\left(t_{2}\right)$ foi de 71,4 anos, no qual a distribuição diamétrica observada e projetada evidencia o seu avanço natural na composição da floresta. Da mesma forma, planos de manejo podem ser direcionados levando-se em conta a adaptabilidade natural da família, de modo a potencializar sua exploração, que tem crescido significativamente devido a seus produtos para fins medicinais, culinários, aromáticos e madeireiros de alto valor agregado (MARQUES, 2001).

A Araucaria angustifolia, por sua vez, manteve um padrão bimodal em sua distribuição diamétrica (Figura 3), característico de sua autoecologia. O crescimento em diâmetro manteve uma tendência de aumento com o avanço das classes diamétricas. Para a classe de 39,4-44,4 cm, ocorreu uma redução na densidade e no crescimento, em relação às classes adjacentes, significando que o menor crescimento está associado à maior mortalidade, sendo que o contrário também foi observado, como visto na classe $49,5 \vdash 54,4 \mathrm{~cm}$.

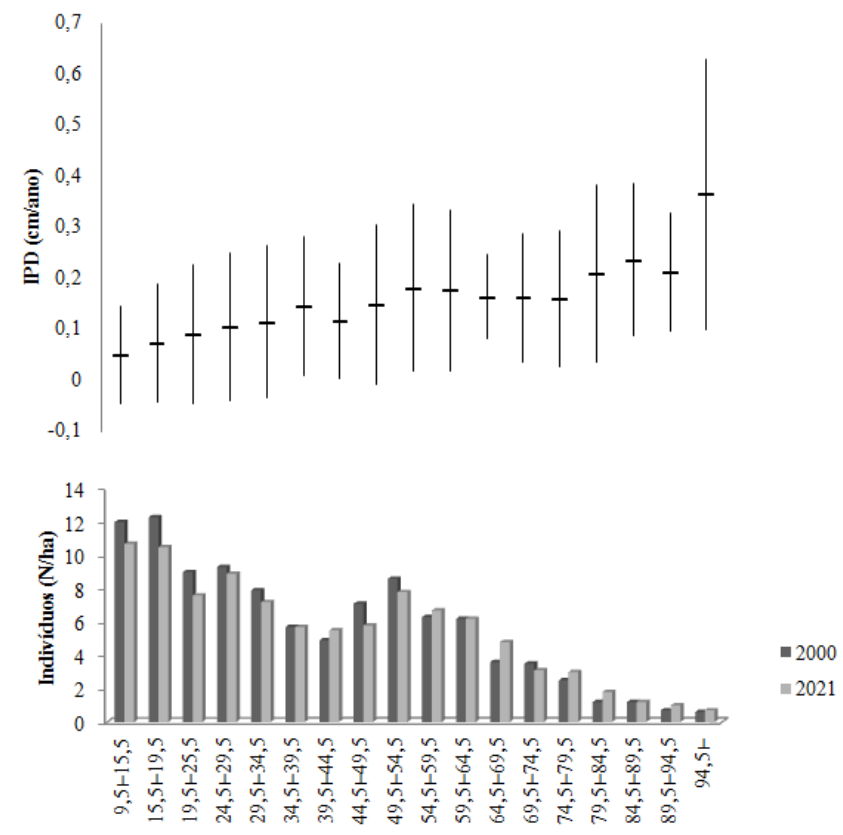

Classes de diâmetro (cm)

Figura 3. Crescimento em classes diamétricas e distribuição diamétrica para Araucaria angustifolia na Floresta Ombrófila Mista de São Francisco de Paula, RS.

Figure 3. Diametric growth and diameter distribution for Araucaria angustifolia in a Mixed Ombrophylous Forest of São Francisco de Paula, RS, Brazil.

Por meio da análise da estrutura diamétrica, observa-se redução do número de indivíduos nas classes diamétricas inferiores, entre os anos de 2000 a 2021, devido à mortalidade acentuada nelas. $\mathrm{O}$ oposto é observado nas classes superiores para o mesmo período, no qual ocorre aumento de densidade, resultante do crescimento e migração.

O período de meia vida $\left(t_{0,5}\right)$ calculado para Araucaria angustifolia foi de 332 anos, superior ao encontrado para a floresta, significando maior desequilíbrio na relação entre mortalidade e ingresso. Logo, embora a mortalidade da Araucaria angustifolia seja responsável por 6,9\% do total de indivíduos 
mortos, representa apenas $1 \%$ do número de recrutamentos, comprovando que sua elevada densidade prolonga o período de meia vida.

A maior classe diamétrica manteve o maior crescimento (IPD $=0,365 \mathrm{~cm} / \mathrm{ano}$ ) e maiores desvios, que podem ser atribuídos à condição de ser uma classe aberta. Já o menor crescimento foi encontrado para a menor classe de diâmetro (IPD $=0,050 \mathrm{~cm} / \mathrm{ano}$ ).

Apesar da eminente redução de indivíduos no decorrer do avanço sucessional da floresta, o crescimento diamétrico médio $(\overline{\mathrm{IPD}})$ da espécie foi igual a $0,159 \mathrm{~cm} / \mathrm{ano}$, inferior ao encontrado para a floresta e família Lauraceae. Figueiredo Filho et al. (2003) descreveram valor de crescimento para Araucaria angustifolia próximo ao encontrado no presente estudo, igual a 0,129 cm/ano.

Corroborando as características sucessionais da Araucaria angustifolia, Ávila et al. (2011) mencionam a grande ocorrência de sementes dispersas da espécie na área de estudo, porém a regeneração natural da espécie é baixa, devido à escassa disponibilidade de luz. Nesse sentido, Narvaes et al. (2005) enfatizam a necessidade de implementação de tratamentos silviculturais capazes de beneficiar o desenvolvimento da espécie na floresta, pela aplicação de técnicas de manejo devido ao seu alto potencial exploratório.

\section{CONCLUSÕES}

- À medida que a floresta avança em seus processos sucessionais, ocorre o autodesbaste, resultando na perda de densidade, porém com aumento em área transversal, devido ao crescimento diamétrico dos indivíduos remanescentes, até que o momento de equilíbrio seja alcançado.

- A espécie Araucaria angustifolia apresenta dificuldade em seu recrutamento na floresta, embora mantenha tendência de aumento de área transversal, configurando-se a tendência de gradual substituição da espécie.

- A família Lauraceae deve aumentar sua importância na floresta, devido a seu superior crescimento e recrutamento quando comparado com a mortalidade.

- A floresta apresentou intermediário crescimento diamétrico ( $\overline{\mathrm{IPD}}=0,175 \mathrm{~cm} / \mathrm{ano}$ ), superior ao crescimento da espécie Araucaria angustifolia $(\overline{\mathrm{IPD}}=0,159 \mathrm{~cm} / \mathrm{ano})$ e inferior ao crescimento $(\overline{\mathrm{IPD}}=0,179 \mathrm{~cm} / \mathrm{ano})$.

- A metodologia da razão de movimentação dos diâmetros indica eficiência nas projeções, relevantes para o manejo florestal e avaliações ecológicas.

\section{REFERENCIAS}

ÁVILA, A. L.; ARAÚJO, M. M.; LONGHI, S. J.; GASPARIN, E. Agrupamentos florísticos na regeneração natural em remanescente de Floresta Ombrófila Mista, RS, Brasil. Scientia Florestalis, Piracicaba, v. 39, n. 91, p. 331 - 342, 2011.

AUSTREGÉSILO, S. L.; FERREIRA, R. L. C.; SILVA, J. A.; SOUZA, A. L.; MEUNIER, I. M. J.; SANTOS, E. de S. Comparação de métodos de prognose da estrutura diamétrica de uma Floresta Estacional Semidecidual secundária. Revista Árvore, Viçosa, v. 28, n. 2, p. 227 - 232, 2004.

BARTH FILHO, N. Monitoramento do crescimento e da produção em Floresta Ombrófila Mista com uso de parcelas permanentes. 99 f. Dissertação (Mestrado em Ciências Florestais) - Universidade Federal do Paraná, Curitiba, 2002.

BEHLING, H.; LICHTE, M. Evidence of dry and cold climatic conditions at glacial times in Tropical southeastern Brazil. Quaternary Research, Seattle, v. 48, n. 3, p. 348 - 358, 1997.

BEHLING, H.; BAUERMANN, S. G.; NEVES, P. C. Holocene environmental changes in the São Francisco de Paula region, southern Brazil. Journal of South American Earth Sciences, Orford, v. 14, 2001 p. $631-639$.

BEHLING, H.; JESKE-PIERUSCHKA, V.; SCHÜLER, L.; PILLAR, V. de P. Dinâmica dos campos no sul do Brasil durante o Quaternário Tardio. In: PILLAR, V. de P.; MÜLLER, S. C.; CASTILHOS, Z. M. de S.; JACQUES, A. V. A. Campos Sulinos: conservação e uso sustentável da diversidade. Brasília: Ministério do Meio Ambiente, 2009. p. 13 - 42. 
EBLING, A. A.; WATZLAWICK, L. F.; RODRIGUES, A. L.; LONGHI, S. J.; LONGHI, R. V.; ABRÃO, S. F. Acuracidade da distribuição diamétrica entre métodos de projeção diamétrica em Floresta Ombrófila Mista. Ciência Rural, Santa Maria, v. 42, n. 6, p. 1020 - 1026, 2012.

EMPRESA BRASILEIRA DE PESQUISA AGROPECUÁRIA (EMBRAPA). Centro Nacional de Pesquisa de Solos. Sistema Brasileiro de classificação de solos. Rio de Janeiro: Embrapa Solos, 2006. 296 p.

FIGUEIREDO FILHO, A.; HUBIE, S. do R.; SCHAAF, L. B.; FIGUEIREDO, D. J.; SANQUETTA, C. R. Avaliação do incremento em diâmetro com o uso de cintas dendrométricas em algumas espécies de uma Floresta Ombrófila Mista localizada no Sul do Estado do Paraná. Revista Ciências Exatas e Naturais, Guarapuava, v. 5, n. 1, p. 69 - 84, 2003.

GALVÃO, F.; AUGUSTIN, C. A gênese dos campos sulinos. Floresta, Curitiba, v. 41, n. 1. p. 191 - 200, 2011.

GENTRY, A. H.; TERBORGH, J. 1990. Composition and dynamics of the Cosha Cashu mature. floodplain forest. In: GENTRY, A. H. Four Neotropical Rainforests. New Haven: Yale University Press, 1990. p. 542 - 564.

KAUL, P. F. T. Geologia. In: IBGE. Instituto Brasileiro de Geografia e Estatística. Região Sul. Rio de Janeiro: IBGE, 1990. p. 29 - 54.

KORNING, J.; BALSLEV, H. Growth and mortality of trees in Amazonian tropical rain forest in Ecuador. Journal of Vegetation Science, Knivsta, v. 4, p. 77 - 86, 1994.

KLEIN, R. M. Mapa fitogeográfico do Estado de Santa Catarina. Itajaí: Herbário Barbosa Rodrigues, 1978. $24 \mathrm{p}$.

MAGNAGO, L. F. S.; SIMONELLI, M.; MARTINS, S. V.; MATOS, F. A. R.; DEMUNER, V. G. Variações estruturais e características edáficas em diferentes estádios sucessionais de floresta ciliar de Tabuleiro, ES. Revista Árvore, Viçosa, v. 35, n. 3, p. 445 - 456, 2011.

MALUF, J. R. T. Nova classificação climática do Estado do Rio Grande do Sul. Revista Brasileira de Agrometeorologia, Santa Maria, v. 8, n. 1, p. 141 - 150, 2000.

MARQUES, C. A. Importância econômica da Família Lauraceae Lindl. Floresta e Ambiente, Seropédica, v. 8, n. 1, p. 195 - 206, 2001.

MOSCOVICH, F. A. Dinâmica de crescimento de uma Floresta Ombrófila Mista em Nova Prata, RS. 135 f. Tese (Doutorado em Manejo Florestal) - Universidade Federal de Santa Maria, Santa Maria, RS, 2006.

NARVAES, I. S.; BRENA, D. A.; LONGHI, S. J. Estrutura da regeneração natural em Floresta Ombrófila Mista na Floresta Nacional de São Francisco de Paula, RS. Ciência Florestal, Santa Maria, v. 15, n. 4, p. $331-342,2005$.

OLIVEIRA FILHO, A. T. Dinâmica da comunidade e populações arbóreas da borda e interior de um remanescente florestal na Serra da Mantiqueira, Minas Gerais, em um intervalo de cinco anos (19992004). Revista Brasileira de Botânica, São Paulo, v. 30, n. 1, p. 149 - 161, 2007.

RAMBO, S. J. B. A fisionomia do Rio Grande do Sul. São Leopoldo: Unisinos, 2005. 486 p.

SCHAAF, L. B.; FIGUEIREDO FILHO, A.; SANQUETTA, C. R.; GALVÃO, F. Incremento diamétrico e em área basal no período 1979-2000 de espécies arbóreas de uma floresta Ombrófila Mista localizada no Sul do Paraná. Floresta, Curitiba, v. 35, n. 2, p. 271 - 290, 2005.

SCOLFORO, J. R.; PULZ, F. A.; MELO, J. M. de. Modelagem da produção, idade das florestas nativas, distribuição espacial das espécies e a análise estrutural. In: SCOLFORO, J. R. Manejo Florestal. Lavras: UFLA/FAEPE, 1998. p. 189 - 246.

SOARES, R. V. Considerações sobre a regeneração natural da Araucaria angustifolia. Floresta, Curitiba, v. 10, n. 2 , p. $11-18,1979$. 
